\title{
CIDADES SUSTENTÁVEIS: LIMITES E POSSIBILIDADES CONCEITUAIS E REGULATÓRIOS
}

\author{
Maria Claudia da Silva Antunes de Souza ${ }^{1}$ \\ Priscilla Linhares Albino ${ }^{2}$
}

\section{RESUMO}

A pesquisa tem por objeto a análise das cidades que estiveram em evidência desde o final do século passado, quando foram constatados problemas decorrentes do crescimento desordenado. Assim, o objetivo é investigar quais os desafios para consolidar uma cidade sustentável e lançar luzes para que a sociedade, o Poder Público e as empresas possam desenvolver e se comprometer com projetos, ações, políticas e planos urbanos estruturados nos marcos regulatórios, buscando um espaço urbano harmônico e equilibrado, com acesso a direitos fundamentais e exercício irrestrito à cidadania. Quanto à metodologia, foi utilizada a base lógica indutiva por meio da pesquisa bibliográfica.

PALAVRAS-CHAVE: Cidade Sustentável; Sustentabilidade; Desenvolvimento; Urbanismo; Meio Ambiente.

\section{SUSTAINABLE CITIES: LIMITS AND CONCEPTUAL AND REGULATORY POSSIBILITIES}

\begin{abstract}
The aim of the research is to analyze the cities that have been in evidence since the end of the last century, when problems arising from disordered growth were observed. Thus, the present study wants to investigate the challenges to consolidate a sustainable city and to shed light on society, government and companies to develop and commit to projects, actions, policies and urban plans structured within regulatory frameworks, seeking a harmonious and balanced urban space, with access to fundamental rights and unrestricted exercise of citizenship. As for the methodology, the inductive logic base was used through bibliographic research.
\end{abstract}

KEY WORDS: Sustainable City; Sustainability; Development; Urbanism; Environment.

\section{INTRODUÇÃO}

Ao longo da história, os centros urbanos, tema central deste artigo, tornaram-se objeto de intensos fluxos de população na busca de melhores expectativas de vida, tendo o

\footnotetext{
${ }^{1}$ Doutora e Mestre em Derecho Ambiental y de la Sostenibilidad pela Universidade de Alicante - Espanha. Mestre em Ciência Jurídica pela Universidade do Vale do Itajaí - Brasil, Graduada em Direito pela Universidade do Vale do Itajaí - Brasil. Professora Permanente do Programa de Pós-Graduação Stricto Sensu em Ciência Jurídica, nos cursos de Doutorado e Mestrado e, na Graduação no Curso de Direito da Universidade do Vale do Itajaí - UNIVALI. Coordenadora do Grupo de Pesquisa e Extensão Paidéia cadastrado no CNPq. Coordenadora do Grupo de Pesquisa - Direito Ambiental, Transnacionalidade e Sustentabilidade - cadastrado no CNPq/EDATS/UNIVALI. Advogada.

${ }^{2}$ Doutoranda em Ciência Jurídica pela UNIVALI. Mestre em Direito pela Universidade Federal de Santa Catarina (UFSC), Mestre em Saúde e Meio Ambiente pela Universidade da Região de Joinville (UNIVILLE).

Revista de Direito e Sustentabilidade | e-ISSN: 2525-9687 | Salvador | v. 4 | n. 1 | p. 95 - 109 | Jan/Jun. 
crescimento ocorrido diante da ausência de regras urbanísticas e em nítido desrespeito ao ambiente natural, fato que encontrou explicação na ressonância do desenvolvimento.

Nesse contexto, as consequências foram sentidas em diversas cidades de todo o mundo - e também do Brasil - que passaram a contar, cada vez mais, com a ocupação informal, a exclusão social, pouquíssima ou nenhuma área verde e, com a chegada da modernidade e a adoção do modelo capitalista, a ampla impermeabilização do solo em seus cenários, a falta de mobilidade e acessibilidade, dentre outros problemas, afastando, assim, a sustentabilidade ambiental, social e econômica.

Somente a partir de meados do século passado é que começaram a ser editadas mundialmente normas jurídicas de cunho urbanístico, a fim de regulamentar a matéria e promover a paz social nos centros urbanos. (HUMBERT, 2017, p. 3).

Considerando o cenário mencionado, o objetivo deste artigo é trazer à reflexão os desafios conceituais e regulatórios para que as cidades alcancem a sustentabilidade e possam garantir aos seus cidadãos espaços que promovam a paz social, mesmo que para isso esses espaços tenham que se reinventar.

Por este motivo, o problema da pesquisa é como equalizar a celeuma advinda do crescimento desordenado das cidades e a necessidade de sua adequação aos marcos regulatórios existentes, sem perder de vista o bem-estar da coletividade, a diminuição das desigualdades e da exclusão social? E, ainda, tudo em consonância com possibilidades naturais sustentáveis?

Há hoje inúmeras iniciativas positivas, mormente nos grandes centros urbanos, em prol de ambientes sustentáveis. Contudo, o envolvimento da sociedade, do Poder Público, das empresas e de diversos organismos sociais é imprescindível para que as cidades se tornem ambientes sustentáveis e adequados às regras legais em vigor. Assim, é imprescindível a atuação dos aludidos agentes em prol da sustentabilidade urbana ${ }^{3}$ voltada para o bem comum da coletividade, com a finalidade de buscar soluções aos obstáculos vivenciados diariamente nas cidades, tais como poluição, exclusão, produção de lixo e falta de espaços arborizados, que geram desequilíbrios e conflitos sociais, econômicos e ambientais, o que se apresentará

\footnotetext{
${ }^{3}$ Cumpre esclarecer que o conceito de sustentabilidade e, também, de cidade sustentável, ainda não é de consenso na doutrina e jurisprudência pátria. Nesse trabalho utilizaremos o conceito e o aporte teórico reunido por José Eli da Veiga, na obra A desgovernança mundial da sustentabilidade. 1. ed. São Paulo: Editora 34, 2013.

Revista de Direito e Sustentabilidade | e-ISSN: 2525-9687 | Salvador | v. 4 | n. 1 | p. 95 - 109 | Jan/Jun. 
ao final deste ensaio.

Entretanto, a justificativa desta pesquisa residiu na dificuldade do cumprimento dos regramentos urbanos e de assegurar políticas públicas que efetivassem a regulamentação, fato que gerou um descompasso significativo entre a cidade sustentável projetada e a real, tornando visível aos olhos de muitos a exclusão social, a violação de direitos e princípios fundamentais, como moradia, dignidade e cidadania.

Para tanto, o estudo está dividido em dois momentos: no primeiro, que aborda o modelo de cidade sustentável e os entraves diante do modelo antropocêntrico que ainda vigora atualmente e que é óbice para a implementação definitiva do espaço urbano ideal. No segundo, a pesquisa busca elucidar quais os desafios que se apresentam para a consecução da cidade sustentável, apontando que a existência de marcos regulatórios é imprescindível, mas que, acima de tudo, o comprometimento dos governantes, das empresas, das entidades e da sociedade, e a compreensão deste espaço como plural, é que farão a diferença entre a sua concretização ou não.

Quanto à metodologia, foi utilizada a base lógica indutiva por meio da pesquisa bibliográfica a ser utilizada no desenvolvimento da pesquisa, compreende o método cartesiano quanto à coleta de dados e no relatório final o método indutivo com as técnicas do referente, da categoria, dos conceitos operacionais da pesquisa bibliográfica e do fichamento. (PASOLD, 2015, p. 97-99)

1. A CIDADE SUSTENTÁ VEL: os entraves diante do antigo modelo antropocêntrico

A ocupação das cidades tem sido alvo de ampla discussão neste início de século. Não somente em razão do significado do termo não ser unívoco mas, sobretudo, em virtude do abundante deslocamento de pessoas para as áreas urbanas nos últimos tempos e da maneira como este tem ocorrido, gerando diversas consequências ambientais, sociais, legais, políticas e culturais.

Convêm-nos, aqui, fazer uma digressão sucinta acerca do modelo antropocêntrico que permeou esse processo. 
O homem, desde o primórdio dos tempos, escolheu os locais que seriam por ele habitados, levando em consideração as suas necessidades de sobrevivência, tais como a existência de água, alimento, segurança e convivência, sem, contudo, conferir a adequada e merecida proteção à natureza que o rodeava, apesar de, desde a época do Império Romano, serem encontradas algumas normas pertinentes ao meio ambiente, especialmente relacionadas a assuntos sanitários. (HUMBERT, 2017)

Da evolução dos acampamentos, passando pelos povoados, até chegar às cidades modernas, o homem percorreu um longo caminho, adaptando o ambiente, e tudo o que havia nele, às suas necessidades e desejos, em busca de melhores condições de vida e segurança para si e sua família. Com a multiplicação das cidades e a intensa e descontrolada exploração dos recursos ambientais, que tiveram como consequência os diversos e recentes fenômenos naturais, tais como o aquecimento global e a crise hídrica, aumentaram os desafios impostos pelo desenvolvimento urbano. Mesmo sendo da própria natureza social do ser humano, desde o primórdio dos tempos, a convivência em cidades (ARISTÓTELES, 2000. p. 47-48), fez-se imperioso que, para o bom e harmonioso convívio, fossem criados conceitos e regramentos.

No início do século passado as cidades ainda eram consideradas, por muitos, espaços insalubres, malvistos, congestionados e permeados por habitações de baixo custo construídas para as classes trabalhadoras, motivo pelo qual diversas famílias preferiam a vida no campo. Com o passar dos tempos, o homem passou, cada vez mais, a modificar esse paradigma e a ocupar os centros urbanos, onde a densidade habitacional, os problemas de transporte e a competição por espaços tornou-se pior. (HALL, 2016)

Diante desse cenário, no início dos anos 70, a Organização das Nações Unidas (ONU) envolveu um grande conjunto de países para discutir a sustentabilidade das cidades e criar uma agenda global. Desde então, em que pese as adversidades, muitos foram os avanços nesta temática, tendo diversos governantes, empresas, entidades e pessoas físicas incorporado a questão ambiental em seus projetos, ações e modo de viver relacionada ou não ao desenvolvimento.

Qual seria, então, o modelo ideal de cidade sustentável? Primeiramente, faz-se importante registrar que a tríade "cidade, desenvolvimento e sustentabilidade" está envolta em um panorama teórico desafiador, complexo e intrincado. No modelo capitalista atual, a humanidade tem buscado o progresso por meio do desenvolvimento, que, no mais das vezes, não está correlacionado a qualquer preocupação ou responsabilidade com a preservação do 
patrimônio ambiental ou a sua exploração razoável e, tampouco, com os conflitos sociais dai decorrentes.

Uma cidade sustentável, para José Renato Nalini e Wilson Levy B. da Silva Neto (2017, p. 6-7), deveria observar as três grandes interfaces da sustentabilidade - ambiental, econômica e social, no seu planejamento. Isso incluiria, dentre outros, temas como licitação verde, construções sustentáveis, redes de transporte coletivo baseadas em fontes renováveis de energia e destinação adequada de resíduos sólidos e efluentes líquidos, sem deixar de lado a exclusão territorial e a ideia de vulnerabilidade, que se desdobra em vulnerabilidade socioeconômica e civil.

Sob prisma diverso, mas não menos ideal, Carlos Leite (2012) ensina que cidades sustentáveis são necessariamente compactas, densas e que as maiores densidades urbanas representam menor consumo de energia per capita. Para o autor, as cidades mais densas da Europa e da Ásia são, hoje, modelos na importante competição internacional entre as global green cities. E isto porque possuem altas densidades, otimizando as infraestruturas urbanas e propiciando ambientes de maior qualidade de vida promovida pela sobreposição de usos. Contudo, são elas muito mais do que um desejável conjunto de construções sustentáveis, posto que este modelo de cidade deve incorporar parâmetros de sustentabilidade no desenvolvimento urbano público e privado. (LEITE, 2012)

Há, ainda, questões globais que não podem ser esquecidas nesse contexto, tais como as mudanças climáticas, a erosão da biodiversidade ou a multiplicação das zonas oceânicas mortas devido ao excesso de nitrogênio, e que precisam de ações globais, a fim de que o caminho para uma cidade - e um mundo - sustentável seja efetivo. Segundo José Eli da Veiga (2013, p. 11), não há alternativa senão enfrentar o desafio de mudança com muita imaginação e desprendimento, crença que seria infundada se não houvesse indícios de que as próximas gerações estarão mais bem preparadas para essas tarefas do que seus antepassados.

Aliás, nas palavras de Rachel Carson, já no ano de 1962, parecendo antever o descaso contínuo e atual com o meio ambiente, "as futuras gerações provavelmente não perdoarão nossa falta de preocupação prudente com a integridade do mundo natural que sustenta toda a vida.” (2010, p. 28)

Em inúmeros momentos nos deparamos com situações que levam a crer que o ser humano esqueceu a responsabilidade que tem de deixar para os seus filhos e netos um Planeta com tantas possibilidades e diversidade como o que herdou. A criação do homem para uma existência de respeito e em equilíbrio com o ambiente advirá, em grande parte, pelos 
exemplos experimentados em suas relações sociais, especialmente em sua família, onde adquirirá consciência de que fazemos, todos, parte da grande teia da vida.

Será na escola, entretanto, com uma pedagogia que facilite este entendimento, que a educação para uma vida sustentável estimulará tanto o entendimento intelectual da ecologia, como criará vínculos emocionais com a natureza, decorrendo daí a probabilidade de que crianças e adolescentes se tornem cidadãos responsáveis e realmente preocupados com a sustentabilidade da vida. (CAPRA, 2006)

A Organização das Nações Unidas (ONU) afirmou, em relatório publicado em 2014, que construir cidades sustentáveis seria um dos maiores desafios, já que estimou que a contínua urbanização e o crescimento geral da população farão com que 2,5 bilhões de novas pessoas passem a viver em áreas urbanas em 2050, áreas essas que abarcarão mais de 6 bilhões de habitantes dos 9,6 bilhões previstos para a referida data. (ONU, 2014)

Apesar de uma queda no número dos nascimentos de crianças em todo o mundo, o número de habitantes seguiu aumentando, segundo os dados da ONU no ano de 2017, os quais apontam que, nesse ritmo, a população mundial chegará a 8,6 bilhões em 2030, 9,8 bilhões em 2050 e que superará os 11,2 bilhões em 2100, o que faz crer que as próximas décadas trarão mudanças profundas no tamanho e na distribuição da massa global. (ONU, 2017)

É preciso, e urgente, repensar os espaços urbanos e enxergá-los sob uma nova perspectiva, com a finalidade de aproximá-los do ideal que vise a real qualidade de vida dos seus habitantes, com suas múltiplas interações e dimensões, contemplando, assim, diversos interesses.

No Brasil, a cidade sustentável é um direito materializado constitucionalmente e, também, legalmente, mas que encontra sérios obstáculos para se concretizar. A Constituição da República Federativa do Brasil de 1988 (BRASIL, 1988) e, posteriormente, o Estatuto das Cidades (BRASIL, 2001), em atendimento a um histórico de reivindicações populares relacionadas à moradia em condições dignas, reúnem normas que versam sobre a Política Urbana. Há de se registrar que, anteriormente a essas normativas, foi sancionada a Lei 6.766 (BRASIL, 1979), que dispôs sobre o parcelamento do solo e que por muito tempo foi a única normativa considerada para fins urbanos.

O advento desses regramentos, contudo, não impediu que o processo de urbanização brasileiro permanecesse fora do controle das autoridades e o direito subjetivo social de moradia digna e da cidade sustentável não fosse assegurado. (RECH, 2016, p. 13) 
E um dos fatores que concorreram para tanto foi o fato de, quando se faz uma releitura do conceito de cidade, emergir daí uma visão amplamente antropocêntrica, com um ordenamento jurídico na mesma vertente, e ainda muito afastado da visão biocêntrica e holística.

As transformações necessárias voltadas à sustentabilidade devem ser precedidas de um bom diagnóstico e, para tanto, faz-se fundamental uma visão integrada entre a natureza e o homem, onde sejam alinhados o desenvolvimento dos espaços urbanos com o respeito à sustentabilidade em todas as suas dimensões.

Não que no território urbanizado no Brasil não existam bons cenários. Eles existem, mas também convivem com os mais diversos contextos de condições sociais e econômicas. É certo que o País abriga cidades que estão na pré-modernidade, carentes de equipamentos e infraestrutura básica, como sistema de saneamento básico; na modernidade, com foco na dependência da energia fóssil e dos processos industriais tradicionais como vetores de desenvolvimento; e na pós-modernidade, onde o lastro é na economia informacional, nas novas tecnologias de informação e comunicação e nos serviços como eixos de desenvolvimento. Contudo, também é fato que estas três dimensões podem ser encontradas em uma única cidade. (NALINI; SILVA NETO, 2017, p. 8)

E a raiz do problema reside no modelo desordenado e degradador de urbanização do território brasileiro, que precisa ser repensado, a fim de migrar do padrão poluidor para o sustentável. Esse ideal gera, inclusive, danos à qualidade de vida das populações mais pobres, posto que interfere na sua distribuição espacial dentro das cidades. Há autores, como o urbanista italiano Bernardo Secci (2015), que afirmam, até mesmo, que as desigualdades sociais são dos aspectos mais relevantes para que seja revisto o projeto urbano de uma cidade, posto que afetam direitos de cidadania essenciais.

Em que pese vislumbrarmos um discurso biocêntrico no cenário brasileiro, há inúmeras ações, tanto públicas, quanto privadas, adotadas nos centros urbanos, que se baseiam no antropocentrismo, que nos impedem de migrar definitivamente - mesmo que já venhamos fazendo algumas mudanças desde os anos 70 - para uma cidade sustentável, sob o olhar do novo Direito, que contemple novas abordagens, mais sistêmicas, integradoras e holísticas.

\section{DESAFIOS PARA A CONSOLIDAÇÃO DA CIDADE SUSTENTÁVEL:}


Nos centros urbanos, diversos são os temas objeto de pauta pelos governantes e também por toda a Sociedade, dentre eles o saneamento básico, a poluição, educação, o uso da água, a mobilidade, a acessibilidade, o lixo e a regularização fundiária.

Para a consolidação de uma cidade sustentável, onde todos esses aspectos sejam contemplados, adequados e trazidos ao contexto brasileiro, deve haver um projeto, a fim de que as políticas públicas sejam delineadas e, posteriormente, implementadas, tornando-se efetivas e abarcando, assim, as necessidades e os anseios da população com soluções adequadas, eficazes e atuais.

Esse modelo de cidade, em que pese fazer parte da atual pauta da Sociedade e dos governantes, não é algo de fácil definição. Poderia, entretanto, ser de mais simples realização se gestores se desvinculassem do antropocentrismo, observassem normas de política urbana e canalizassem os recursos públicos para fins que não fossem diversos do interesse público, privilegiando realmente o desenvolvimento e a aplicação de soluções urbanas ambiental, social e economicamente sustentáveis. E, nesse contexto deve ser anotado que, enquanto a ética antropocentrista imperar na relação do homem com a natureza, resultará, sempre, em um ambiente desequilibrado e desfavorável ao próprio ser humano.

Não é uma constatação recente o fato de que as áreas verdes valerem mais financeiramente quando ocupadas por edificações que pouco ou nada guardam da relação ética com a natureza. Para essa cultura, o espaço urbano é espaço de criação humana, e cidade é lugar de "homem civilizado" e não de mato e animais. (RECH, 2016. p. 61)

Há, sim, governantes sensíveis à causa ambiental, mas que não conseguem implementar as suas promessas de campanha em prol do bem-estar da comunidade pela qual foram eleitos, em razão da falta de planejamento urbano concreto e eficaz, calcado em normas atuais e em ações que não sofram quebra de continuidade pelo fim do mandato, que respeitem o meio ambiente e que, acima de tudo, privilegiem a qualidade de vida do seres humanos que ali habitam.

Há aqueles, ainda, segundo Peter Hall (2016), ao fazer alusão à solidão geométrica de Brasília, que constroem cidades suntuosas, em prazos exíguos impossíveis, e que privilegiam imensas vias para os automóveis, esquecendo-se até mesmo do pedestre, quiçá da natureza do entorno. (HALL, 2016)

No Brasil, o arcabouço jurídico que trata do espaço urbano compreende a controversa Lei de Parcelamento do Solo, a Constituição da República Federativa do Brasil de 1988 (CRFB/88) e, ainda, o Estatuto das Cidades. Há, contudo, consenso nos meios 
acadêmicos especializados, a exemplo de Maria Paula Dallari Bucci (2002) e José Renato Nalini e Wilson Silva Neto (2017), de que esse aparato permanece incapaz de impor formas adequadas à ocupação das cidades.

Nessa linha, Roberta Terezinha Uvo Bodnar e Zenildo Bodnar (2015), propõem um olhar interdisciplinar que abarque o complexo fenômeno urbano nas suas múltiplas relações na atualidade, posto que é neste ambiente que os desafios são mais intensos e qualificados, decorrendo daí fatos e condutas, bem como consequências, com repercussão significativa na vida das pessoas e dos ecossistemas. (BODNAR e BODNAR, 2015)

A Lei de Parcelamento do Solo (BRASIL, 1979), apesar de ser considerada inconstitucional por diversos autores, dentre eles Adir Ubaldo Rech e Adivandro Rech, ainda permite margem a interpretações errôneas quando é utilizada como o principal instrumento de planejamento urbano no País, admitindo que sejam ignoradas as particularidades locais e a necessidade de espaços verdes que garantam sustentabilidade ambiental. Trata-se de uma Lei antropocêntrica, que destina espaços visando à ocupação humana e aos interesses imobiliários, não assegurando um ambiente ecologicamente equilibrado, tampouco garantindo a preservação da biodiversidade próxima de onde vive o cidadão.

A CRFB/88, ratificando um processo de evolução de consciência da sociedade, dedicou um capítulo inteiro ao meio ambiente (art. 225) e, ainda, em seus artigos 182 e 183 estabeleceu diretrizes, valores básicos e instrumentos mínimos de materialização do direito nas áreas urbanas.

Essas diretrizes, por sua vez, foram regulamentadas pela Lei 10.257/2001, conhecida como Estatuto das Cidades, que adotou a expressão "cidade sustentável" e estabeleceu normas gerais para a política urbana no País, impondo diversos deveres aos gestores públicos. Estabeleceu ela normas de ordem pública e interesse social que regulam o uso da propriedade urbana em prol do bem coletivo, da segurança e do bem-estar dos cidadãos, bem como do equilíbrio ambiental.

Ao apontar a garantia ao direito a cidades sustentáveis, o referido texto explica-o como sendo o direito à terra urbana, à moradia, ao saneamento ambiental, à infraestrutura urbana, ao transporte e aos serviços públicos, ao trabalho e ao lazer, para as presentes e futuras gerações. E prossegue, garantindo a gestão democrática por meio da participação popular e de associações representativas dos vários segmentos da comunidade na formulação, execução e acompanhamento de planos, programas e projetos de desenvolvimento urbano. 
Constata-se, assim, ao se estabelecer um paralelo entre o plano jurídico e o fático, que o direito à cidade, em diversos locais, permanece distante do formato adequado de planejamento do espaço urbano sustentável ideal, mormente se considerarmos que os Planos Diretores, importante instrumento de efetivação da política urbana, que foram elevados constitucionalmente ao status de instrumento básico da política urbana, precisam sair do papel, a fim de resolver os problemas de exclusão social, da violação de direitos e princípios fundamentais, como moradia, dignidade e cidadania, respeitando-se todas as suas possibilidades jurídicas de planejamento. (RECH, 2016. p. 15)

Esse instrumento foi regulamentado pelo Estatuto da Cidade (arts. 39 até 42), onde restou delineado o seu conteúdo mínimo e a obrigatoriedade de sua revisão a cada dez anos, com a finalidade de atualizá-lo aos novos contextos decorrentes da evolução social urbana, tornando-se cada vez mais holísticos e integradores.

Nesse sentido, deve-se atentar às ocupações permitidas tão somente com finalidade eleitoreira e para cobrar tributos e, também, àqueles que não possuem recursos para comprar uma moradia, segundo as normas urbanísticas previstas nos Planos Diretores, que são excluídos do perímetro urbano.

Ainda, o não reconhecimento, como cidadã, da parcela da população que mora na área rural, haja vista que totalmente desprotegida de normas de ocupação, o que fere frontalmente o Estatuto da Cidade, no que se refere à sustentabilidade.

Em que pese o Estatuto da Cidade obrigar a elaboração do referido Plano em todo o território do município (art. 40, parágrafo $2^{\circ}$ ), a área rural permanece ignorada ante o argumento de pertencer à seara do Direito Agrário. Contudo, para Adir Ubaldo Rech e Adivandro Rech, trata-se de um equívoco porquanto, apesar de se destinarem à finalidade agrária, por questões de sustentabilidade pode e deve ter outras atividades que não são de Direito Agrário, mas que tem outra natureza, outra finalidade, de interesse local diverso e que por isso devem ser regulamentadas pelo Poder Público municipal, através do Plano Diretor. (2016, p. 305-310)

Para Carlos Leite (2012, p. 6-8) o desenvolvimento urbano sustentável impõe o desafio de refazer a cidade existente, reinventando-a de modo inteligente e inclusivo. Inovações urbanas já ocorreram em todo o mundo e provam que é possível uma cidade se transformar e renascer, tal como ocorreu com Barcelona, Vancouver, Nova York, Bogotá e Curitiba. 
É factível a regeneração urbana, nos moldes do que ocorreu nos espaços apontados acima, onde as cidades planejam a expansão futura, utilizando seus recursos de forma sustentável e fornecendo os serviços essenciais, apesar de o Município, mesmo possuindo responsabilidade da iniciativa de criar normas que definam uma cidade sustentável, possuir autonomia restrita para financiar políticas públicas e também para legislar.

Mesmo diante desse desafio, os municípios que almejam a sustentabilidade ambiental precisam se comprometer com o desenvolvimento de projetos, ações, políticas e programas públicos e privados voltados à educação socioambiental de qualidade e que contemplem uma cidade para todos.

Nesse cenário, o foco mantido no vetor econômico deve migrar para o que vise a sustentabilidade ambiental e a qualidade de vida, onde prevaleça o equilíbrio e a razoabilidade entre os três vértices: ambiental, social e econômico.

Para Enrique Leff (2010, p. 20), seria imprescindível o estabelecimento de um diálogo entre a economia e o meio ambiente, a fim de que se desenvolvesse uma proposta para a construção de outra economia baseada em uma racionalidade ambiental, onde o equilíbrio econômico, a preservação da biodiversidade e a qualidade de vida dos seres humanos fossem fundamentais para a sustentabilidade da própria economia.

Ao desconsiderar reiteradamente a ética ambiental, a sociedade sequer se dá conta de que os constantes alagamentos nas cidades, estão em contradição com à falta de água nas torneiras, a degradação dos espaços urbanos e o isolamento do homem num ambiente artificialmente criado. (RECH e RECH, 2016)

Até quando o homem acreditará que poderá viver sem estabelecer uma relação ética com a natureza - com a teia da vida, construindo cidades que não priorizam a existência, a dignidade humana, a natureza e o bem-estar?

Certo é que atravessamos um momento de transição, em que há inúmeros setores da sociedade empenhados em mudanças voltadas à transformação visando à sustentabilidade dos espaços urbanos. Há, também, algumas cidades que já atingiram e se empenham em permanecer no ideal ambiental projetado. Entretanto, o caminho é longo e íngreme, posto que há muito por fazer para vencer a herança colonial arraigada em nossos espaços urbes. Não somente atingir o objetivo, mas, do mesmo modo, permanecer nele, é um desafio.

Para Peter Hall (2016, p. 31), “após cem anos de debates acerca de como planejar a cidade, após reiteradas tentativas - embora equivocadas e distorcidas - de pôr ideias em 
prática, damo-nos conta de que estamos quase de volta ao ponto de partida." Contudo, para o autor, a cidade do milênio é um lugar imensamente diferente, e inquestionavelmente superior, quando comparada com as cidades do século passado.

\section{CONSIDERAÇÕES FINAIS}

Há aproximadamente 45 anos que se discute a temática das cidades sustentáveis em escala internacional, através da Organização das Nações Unidas (ONU) que propôs uma agenda global a ser desenvolvida. É possível perceber uma evolução sobre este tema, contudo ainda, há muito por fazer, em especial, na adoção efetiva de um modelo de desenvolvimento sustentável que valorize e incentive as tecnologias limpas e de baixo impacto ambiental, como a geração de energia renovável ou tratamento de resíduos sólidos.

Com a crescente concentração da população nos centros urbanos e à diversidade de problemas técnicos e políticos relacionados a esta dinâmica, procurou-se, discutir e refletir os desafios conceituais e regulatórios para que as cidades alcancem a sustentabilidade e possam garantir aos seus cidadãos espaços que promovam a paz social, mesmo que para isso esses espaços tenham que se reinventar.

É necessário ainda, compreender realmente o conceito de cidade sustentável e, os desafios para sua efetividade, conquistando espaços para o desenvolvimento de instrumento normativo hábil para disciplinar a matéria. Cidades sustentáveis são possíveis, mas para isto é necessário que se reinventem e se sustentem sobre os pilares social, ambiental e econômico. A revolução dos espaços urbanos não é fácil, nem simples, mas é possível.

Para tanto, a participação e o envolvimento da sociedade, do Poder Público, das empresas e de diversos organismos sociais é imprescindível, a fim de que as cidades se tornem ambientes democráticos, sustentáveis em todas as suas dimensões e adequados às regras legais em vigor.

Somente se atingirá o objetivo constitucional de uma sociedade justa, humana e solidária, onde o bem comum e a busca por soluções aos obstáculos vivenciados diariamente nos espaços urbanos, quando política públicas adequadas e eficazes forem implementadas por governantes sérios e comprometidos com a sociedade e quando essa também se der conta da sua parcela de responsabilidade para transformar o mundo que habita.

Os centros urbanos deixarão de ser espaços que geram desequilíbrios e conflitos de ordem geral quando se tornarem lugares que privilegiem a ética ambiental, a pluralidade, a diversidade do comportamento humano e as suas inter-relações garantindo, assim, aos seus 
moradores espaços equilibrados e fontes de uma vida com qualidade.

A reinvenção das cidades, na prática, ainda depende, e muito, do olhar e do proceder dos gestores e dos habitantes estarem ou não vinculados ao antropocentrismo. Somente a concepção do ambiente urbano associado aos comportamentos humanos e suas inter-relações, bem como aos valores sociais, naturais e econômicos, é capaz de produzir um espaço que desencadeie o sentimento de pertencimento em seus habitantes.

É preciso, também, a apreensão e a compreensão de normas e regulamentos, dentre eles a existência de um zoneamento ambiental que anteceda o Plano Diretor, a fim de que a cidade que se almeja caminhe para a sustentabilidade, calcada nos pilares ambiental, social e econômico. E, mais que isso, é necessário que ocorra uma transformação positiva, inovadora e que convirja para a interação equilibrada entre o homem, o desenvolvimento e o ambiente natural.

\section{REFERÊNCIAS}

ARISTÓTELES. A Política. Traduzido por Carlos Garcia Gual e Aurélio Pérez Jimènez. Madrid: Alianza, 2000.

BECK, Ulrich. Sociedade de risco: rumo a uma outra modernidade. Tradução de Sebastião Nascimento. São Paulo: Editora 34, 2011.

BODNAR, Roberta Terezinha Uvo; BODNAR, Zenildo. A epistemologia interdisciplinar do direito à cidade. XXIV Congresso Nacional do CONPEDI - UFMG/FUMEC/Dom Helder Câmara. In: Direito urbanístico, cidade e alteridade. SALEME, Edson Ricardo; LEITE, Flavia Piva Almeida; GAIO, Daniel. Florianópolis: CONPEDI, 2015.

BUCCI, Maria Paula Dallari. Gestão democrática da cidade. In: DALLARI, A.A.; FERRAZ, S. Estatuto da Cidade. São Paulo: Malheiros, 2002.

BRASIL. Constituição da República Federativa do Brasil de 1988. Texto consolidado até a EC n. 91/2016. Portal do Senado Federal: Legislação. Brasília, DF.Disponível em: https://www2.senado.leg.br/bdsf/bitstream/handle/id/518231/CF88_Livro_EC91_2016.pdf Acesso em: 07 mar. 2018.

Lei n. 6.766, de 19 de dezembro de 1979. Disponível em: http://www.planalto.gov.br/CCivil 03/leis/L6766.htm?TSPD 101 R0=876067c2e28dff6751 66615f140acd07hQY00000000000000001a2569b3ffff00000000000000000000000000005ac 15dd6000bfadc59 Acesso em: 30 mar. 2018.

Lei n. 10.257, de 10 de julho de 2001. Regulamenta os arts. 182 e 183 da Constituição Federal, estabelece diretrizes gerais da política urbana e dá outras providências. Portal da Presidência da República do Brasil: Legislação. Brasília, DF. Disponível em: 
http://www.planalto.gov.br/Ccivil_03/leis/LEIS_2001/L10257.htm Acesso em: 07 mar. 2018.

BODNAR, Zenildo e CRUZ, Paulo Márcio. Pensar globalmente y actuar localmente: El Estado transnacional ambiental em Ulrich Bech. Revista Aranzadi de Derecho Ambiental, v. 1, p. 51 a 59, (Espanha), 2008, p. 11-27.

BOSSELMANN, Klaus. O princípio da sustentabilidade: transformando direito e governança. Tradução de Phillip Gil França. São Paulo: Editora Revista dos Tribunais, 2015.

CARSON, Rachel. Primavera Silenciosa. Traduzido por Claudia Sant'Anna Martins. 1.ed. São Paulo: Gaia, 2010.

CAPRA, Fritjof. Falando a linguagem da natureza: princípios da sustentabilidade. In: STONE, Michael K.; Barlow, orgs. Alfabetização ecológica: a educação de crianças para um mundo sustentável. Tradução de Carmen Fischer. São Paulo: Cultrix, 2006.

CORTESE, Tatiana T. P.; KNIESS, Claudia T.; MACCARI, Emerson A. (orgs.) Cidades inteligentes e sustentáveis. Barueri, SP: Manole, 2017.

GEHL, Jan. Cidades para pessoas. Tradução de Anita Di Marco. 3. ed. São Paulo: Perspectiva, 2015.

HALL, Peter. Cidades do amanhã: uma história intelectual do planejamento e do projeto urbanos no século XXI. Tradução de Maria Alice Junqueira Bastos, Pérola de Carvalho e Anita Guimarães. 4. ed. São Paulo: Perspectiva, 2016.

HUMBERT, Georges Louis Hage. Curso de direito urbanístico e das cidades. 1. ed. Rio de Janeiro: LMJ Mundo Jurídico, 2017.

LEFEBVRE, Henri. O direito à cidade. 5. ed. São Paulo: Centauro, 2016.

LEFF, Henrique. Discursos sustentáveis. Tradução de Silvana Cabucci Leite. São Paulo: Cortez, 2010.

LEITE, Carlos; AWAD, Juliana di Cesare Marques. Cidades sustentáveis, cidades inteligentes: desenvolvimento sustentável num planeta urbano. Porto Alegre: Bookman, 2012.

NALINI, José Renato; SILVA NETO, Wilson Levy Braga da. Cidades inteligentes e sustentáveis: desafios conceituais e regulatórios. In: Cidades Inteligentes e sustentáveis. São Paulo: Manole, 2017.

ONU. Organização das Nações Unidas. Cidades terão mais de 6 bilhões de habitantes em 2050. 2014. Disponível em: https://nacoesunidas.org/cidades-terao-mais-de-6-bilhoes-dehabitantes-em-2050-destaca-novo-relatorio-da-onu/ Acesso em: 6 mar. 2018.

ONU. Organização das Nações Unidas. 2017. World Population Prospects The 2017 Revision. Disponível em: 
https://esa.un.org/unpd/wpp/Publications/Files/WPP2017_KeyFindings.pdf. Acesso em: 06 mar. 2018.

PEREIRA, Elson M. (Org.) As cidades e a urbanização no Brasil: passado, presente, futuro, Florianópolis, Ed. Insular, 2011.

PHILIPPI Jr., Arlindo; SAMPAIO, Carlos A. C., \& FERNANDES, Valdir. (Org.). Gestão de natureza pública e sustentabilidade. São Paulo: Editora Manole. Coleção Ambiental, 2012.

RECH, Adir Ubaldo; RECH, Adivandro. Cidade sustentável, direito urbanístico e ambiental: instrumentos de planejamento. Caxias do Sul, RS: Educs, 2016.

SAULE JÚNIOR, Nelson. A relevância do Direito à Cidade na Construção de Cidades Justas, democráticas e sustentáveis. In: Direito Urbanístico - Vias jurídica das Políticas Urbanas. Porto Alegre: Sergio Antonio Fabris, p. 27-61, 2007.

SECCHI, Bernardo. La ciudad de los ricos y la ciudad de los pobres. Tradução de Tereza Arenillas Parra y Francisco Lópes Groh. Madrid: Catarata, 2015.

SCHWAB, Klaus. A quarta revolução industrial. Tradução de Daniel Moreira Miranda. São Paulo: Edipro, 2016.

VEIGA, José Eli da. A desgovernança mundial da sustentabilidade. 1. ed. São Paulo: Editora 34, 2013. 